\title{
ANÁLISIS HISTOPATOLÓGICO EN Litopenaeus vannamei INFECTADO CON Vibrio parahaemolyticus ${ }^{1}$
}

\author{
Nelson Peña-Navarro², Alexander Varela-Mejías ${ }^{3}$
}

\begin{abstract}
RESUMEN
Análisis histopatológico en Litopenaeus vannamei infectado con Vibrio parahaemolyticus. El objetivo de este trabajo fue describir los principales resultados histopatológicos obtenidos de las diversas respuestas inmunológicas y efectos citopáticos en L. vannamei, después de una infección inducida con $V$. parahaemolyticus. La inoculación bacterial se realizó en el Centro de Investigación en Ciencias del Mar y Limnología de la Universidad de Costa Rica, entre junio y agosto del 2011. Para la investigación se utilizaron 40 camarones extraídos de fincas ubicadas en la Península de Nicoya; a cada uno se le inyectó en promedio 2,0x $10^{6}$ UFC de $V$. parahaemolyticus. Al finalizar el periodo de infección, se realizaron los análisis histopatológicos en branquias, epitelio subcuticular, hepatopáncreas, intestino, órgano linfoide, tejido hematopoyético, músculo estriado, tejido nervioso, corazón, entre otras. Los principales hallazgos a nivel histológico fueron hemocitos melanizados, infiltración hemocítica, melanosis, esferoides tipo A, B y C, mionecrosis coagulativa, fagocitosis, picnosis, entre otras, útiles para determinar el estado sanitario de los camarones y en particular, el efecto citopático de $V$. parahaemolyticus en infecciones sistémicas.
\end{abstract}

\begin{abstract}
Histopathological analysis in Litopenaeus vannamei infected with Vibrio parahaemolyticus. The objective of this work was to describe the main histopathological results obtained from the different immune responses in L. vannamei after infection induced with V.parahaemolyticus. Inoculation bacterial was conducted in the Research Center for Ocean Sciences and Limnology at the University of Costa Rica betwen june to august 2011. The research used 40 shrimp of farms located in the Nicoyan Peninsula; each was injected an

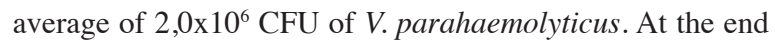
of the period of infection, histopathological analysis were conducted on gills, subcuticular epithelium, hepatopancreas, intestine, gut lymphoid organ, hematopoietic tissue, striated muscle, nervous tissue, heart, among others. The main histological findings were melanized hemocytes, haemocyte infiltration, melanosis, spheroids type A, B and C, coagulative myonecrosis, pyknosis, among others, useful to determining in the health status of shrimp in particular, cytopathic effect of $V$. parahaemoltycus in systemic infections.
\end{abstract}

Keywords: histopathology, bacterial infection in shrimp, vibriosis.

Palabras clave: histopatología, infección bacteriana en camarones, vibriosis.

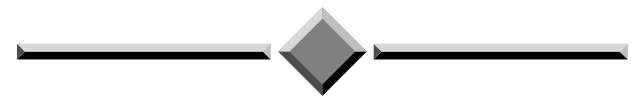

\footnotetext{
Recibido: 18 de febrero, 2014. Aceptado: 5 de agosto, 2014. Parte de la tesis de graduación del primer autor. Universidad de Costa Rica. 2 Universidad Técnica Nacional, Dirección de Investigación. Puntarenas, Costa Rica.npena@utn.ac.cr

3 Laboratorio de Patologías y Parasitología de Crustáceos, Guanacaste, Costa Rica. alexander.varela@gmail.com
}

(C) 2015 Agronomía Mesoamericana es desarrollada en la Universidad de Costa Rica y se encuentra licenciada con Creative Commons Reconocimiento-NoComercial-SinObraDerivada 3.0 Costa Rica. Para más información escríbanos a pccmca@ucr.ac.cr 


\section{INTRODUCCIÓN}

La producción de camarón ha tenido un incremento acelerado a nivel mundial, donde América generó durante el 2008 el 80,7\% de la producción acuícola de camarón blanco Litopenaeus vannamei en el mundo (FAO, 2010). Lo anterior, se ve reflejado en los principales países dedicados a la producción de camarón, donde este tipo de actividades se ha convertido en fuente de alimento y trabajo (Balcázar, 2002).

El incremento en la producción de camarón ha provocado un detrimento en la calidad de aguas, propiciando que las condiciones presentes en los estanques pueden beneficiar el desarrollo de algunas comunidades específicas de bacterias; mismas que pueden ser causa de serios problemas patológicos para los cultivos, especialmente en los estadíos larvales de los camarones (Álvarez et al., 2000; Aguirre et al., 2005). Ante esto, las patologías de tipo bacteriano (Ibarra et al., 2003) han generado un aumento de la incidencia de enfermedades infecciosas (MoralesCovarrubias, 2004; Trujillo et al., 2005). El impacto de las enfermedades bacteriales como Vibrio sp. (Kannapiran et al., 2009; Ganesh et al., 2010; Peña et al., 2013), ha generado grandes pérdidas económicas (Burge et al., 2007; Decamp et al., 2008), reportándose mortalidades de hasta el $100 \%$ de las producciones afectadas (Trujillo et al., 2005).

En Asia y América, múltiples especies de bacterias se han asociado a patologías; sin embargo, en la mayoría de los estudios no se ha demostrado que Vibrio sp. participe como agente primario, considerándose parte de la microflora normal de los animales o del agua de los estanques, y ha sido calificado por ello como un patógeno secundario u oportunista (Soto et al., 2010). Estos autores citan entre las especies patogénicas de vibriosis a $V$. parahaemolyticus, $V$. penaeicida, V. nigripulchritudo, V. alginolyticus, $V$. harveyi y V. campbellii. En Costa Rica, esta situación se ha confirmado en fincas camaroneras ubicadas en el Golfo de Nicoya, vinculado a lo expuesto por el estudio de Nelapati et al. (2012).

Durante los últimos años, ha emergido un caso particular de vibriosis denominado Síndrome de Mortalidad Temprana o Síndrome de la Necrosis Hepatopancreática Aguda (EMS/AHPNS, por sus siglas en inglés), impactando severamente a las producciones en las zonas afectadas. Este fue reportado por primera vez en el año 2009 en camarones juveniles de cultivo en China (Lightner et al., 2012) en las especies Penaeus monodon y Litopenaeus vannamei. En los años siguientes se propagó a países cercanos, afectando a Vietnam en el 2010, Malasia en el 2011, Tailandia en el 2012 y recientemente a México en el 2013 (FAO, 2013). Los estudios realizados durante el 2013 identificaron como causante de la enfermedad, a una cepa altamente virulenta de $V$. parahaemolyticus (FAO, 2013; Tran et al., 2013).

El género Vibrio coexiste normalmente en los animales de cultivo, colonizando principalmente el tracto digestivo, las branquias y la cutícula (MoralesCovarrubias, 2008). El proceso infeccioso se presenta cuando las bacterias logran accesar al interior del organismo, se supone que una de las rutas naturales para ello, es a través del intestino medio y se extiende a los demás órganos vía hemolinfa, causando inicialmente lesiones tales como hepatopáncreas edémico y un alto grado de vacuolización de las células epiteliales de este órgano (Morales-Covarrubias, 2013), el proceso infeccioso avanza dando lugar a infecciones generalizadas, involucrando cutícula, hepatopáncreas, órgano linfoide, glándula antenal, corazón, hemolinfa y músculos (Morales-Covarrubias, 2008).

Una vez que el organismo ingresa al hospedador, el sistema inmune inicia una serie de respuestas, tales como la migración de hemocitos al punto de infección, generando una respuesta inflamatoria, donde se produce la fagocitosis de los patógenos. Cuando la cavidad corporal es invadida por una cantidad masiva de microorganismos, la fagocitosis no es posible, y se desencadena la formación de nódulos hemocíticos, que consisten en la agregación de capas de hemocitos rodeando a los patógenos, de modo que se evita su diseminación y se facilita su destrucción (Barraco et al., 2008).

Estos mismos autores indican que la formación de nódulos está generalmente acompañada por la producción de sustancias tóxicas para los invasores, tales como la melanina, quinonas y hemoquinonas, que se dan como resultado de la activación del sistema fenol oxidasa a través de una compleja serie de reacciones enzimáticas.

Con el fin de comprender los mecanismos patogénicos del género Vibrio, se han realizado algunas investigaciones en las que se han utilizado desafíos por inyección, tal como se ejecutó en EE.UU. 
con la especie Sicyonia ingentis donde se utilizó Vibrio parahaemolyticus en concentraciones de $1 \times 10^{4}$ UFC por animal. Este estudio analizó las lesiones generadas en el intestino medio, reportando desprendimientos de las células epiteliales (Martin et al., 2004). Desafíos similares realizados en México, infectando a L. vannamei con Vibrio harveyi, describen en forma detallada los efectos citopáticos observados (Soto et al., 2012), pero sin determinar el grado de severidad de los mismos.

En este tipo de investigaciones, así como en diagnóstico de rutina, la utilización de análisis histopatológicos se ha convertido en una de las técnicas más comunes para la detección de patologías, principalmente debido a que es una herramienta de diagnóstico que permite detectar el grado de daño tisular y posibles agentes causales de mortalidad (Morales-Covarrubias, 2004; Cuéllar, 2008), de ahí que su implementación genere información relevante para mantener un monitoreo adecuado de las enfermedades emergentes y sirva como mecanismo de identificación oportuna ante las diversas patologías como las ocasionadas por V. parahaemolyticus.

En Costa Rica, se ha aislado V. parahaemolyticus de peces y bivalvos que habitan en el Golfo de Nicoya (Díaz y Valerio, 2002), aguas costeras que abastecen las fincas camaroneras de la región y que eventualmente pudieran ejercer negativamente sobre la producción en L. vannamei. Sin embargo, a la fecha no se ha investigado sobre su relación con la presencia de EMS/AHPND o infecciones sistémicas, debido a que son limitados los monitoreos y análisis de laboratorio en torno a este tipo de enfermedades, lo que genera desconocimiento e incertidumbre sobre el tema.

El objetivo de este trabajo fue describir los principales resultados histopatológicos obtenidos de las diversas respuestas inmunológicas y efectos citopáticos en $L$. vannamei, ante la infección inducida con V. parahaemolyticus.

\section{MATERIALES Y MÉTODOS}

Se realizó una inoculación bacterial en el Centro de Investigación en Ciencias del Mar y Limnología (CIMAR) en la Ciudad de la Investigación, Universidad de Costa Rica, durante los meses de junio y agosto del año 2011.
La infraestructura destinada al desarrollo de esta investigación consistió en un laboratorio de acuarios acondicionado con seis tanques de almacenamiento de aproximadamente 900 litros cada uno, aireación suministrada por un blower de $2,5 \mathrm{hp} \mathrm{y}$ un compresor. Los acuarios fueron cubiertos con una tapa de malla plástica y marco de madera para evitar la fuga de animales y la caída de los mismos en otras peceras o en el suelo.

Este trabajo forma parte de una investigación realizada para evaluar el efecto estimulador de productos naturales en L.vannamei antes de ser infectado con $V$. parahaemolyticus (Peña et al., 2013). En este estudio se puede observar las variables evaluadas y los resultados obtenidos de la fase experimental.

Camarones experimentales: los juveniles de $L$. vannamei utilizados para el estudio se recolectaron en las fincas Cerro Mar 3 y Caraito 2, ubicadas en la zona de Colorado de Abangares $\left(10^{\circ} 16^{\prime} 55^{\prime \prime} \mathrm{N}\right.$ y 84 ${ }^{\circ} 57^{\prime} 42$ " W), Guanacaste, Costa Rica. Previo a su recolección se analizó una muestra de diez camarones por medio de la metodología de análisis en fresco (Cuéllar, 2008), se implementó el examen clínico como un mecanismo que avaló un estado de salud óptimo antes del traslado. La muestra para el estudio fue de cuarenta animales; con intervalos de pesos entre 6,67 a 10,00 g, promedio de 8,32 $\pm 0,57$ (Media \pm DE).

Aclimatación y acondicionamiento en acuarios: luego de recolectar los camarones de manera aleatoria por medio de una atarraya en horas de la mañana (6-7 am), se aclimataron lentamente en bolsas con agua filtrada, de manera que mantuvieran en promedio 25,5 ${ }^{\circ} \mathrm{C}$ de temperatura, $24 \mathrm{ppm}$ de salinidad y oxígeno disuelto saturado.

$\mathrm{Al}$ recibir los camarones en el área experimental del CIMAR, se aclimataron por espacio de dos días en dos reservorios de 425 litros, cubiertos con tapas de malla plástica. Luego se igualó paulatinamente la temperatura, oxígeno y salinidad del agua contenida en las bolsas, las cuales al final fueron de $27^{\circ} \mathrm{C}, 35$ ppm de salinidad y $6 \mathrm{mg} / \mathrm{l}$ de oxígeno disuelto.

Luego se trasladaron a los acuarios con aireación y temperatura controlada, la primera producida por un sistema central de ventilación y distribuida mediante la utilización de piedras difusoras; mientras el segundo implementando termostatos. Se presentaron promedios de oxígeno disuelto y temperatura de 4,50 $\pm 0,44$ y 29,57 $\pm 0,27$ (Media $\pm \mathrm{DE})$, respectivamente. La salinidad 
fue de $35 \mathrm{ppm}$. Para medir el oxígeno y la temperatura se utilizó un oxigenómetro portátil, mientras que la salinidad se midió con un refractómetro. Finalmente, estos camarones fueron sometidos a un fotoperiodo de $12 \mathrm{~h}$ de luminosidad y $12 \mathrm{~h}$ de oscuridad (iniciando a las 6:00h y finalizando a las 18:00 h).

Examen clínico y análisis en fresco: de acuerdo a la metodología de Cuéllar (2008), se realizaron análisis en fresco a muestras representativas de los camarones y se determinó que no existían enfermedades o lesiones en los animales experimentales. Según la técnica descrita por Morales (2008), se buscaron alteraciones causadas por parásitos y patógenos en las branquias, hepatopáncreas, intestino y músculo.

Cepas de Vibrio parahaemolyticus: las suspensiones de $V$. parahaemolyticus fueron donadas por el Laboratorio de Bacteriología Médica de la Escuela de Microbiología de la Universidad de Costa Rica, las cuales fueron obtenidas a partir de la cepa ATCC 17802.

Se infectaron los camarones inyectándoles una suspensión bacteriana, obtenida a partir de la dilución en solución salina estéril de un concentrado bacterial, hasta lograr el estándar de turbidez 0,5 de Mc Farland. Los camarones se desinfectaron en la zona de inyección con etanol al 70\%, y se inocularon mediante aplicación intramuscular; entre el tercer y cuarto segmento abdominal con una jeringa estéril de $1 \mathrm{cc}$ y con aguja de calibre $29 \mathrm{x}^{1} / 2$ (se evitaron traumatismos excesivos). La solución de bacterias utilizada contenía en promedio $2,0 \times 10^{6} \mathrm{UFC} /$ camarón, similar a la información presentada por Zhang et al. (2012).

Histología: para la fijación y preparación de los animales e histología, se siguió la metodología descrita por Bell y Lightner (1988) y Cuéllar (2008). En el bioensayo se realizaron cortes y montajes para análisis en branquias, epitelio cuticular, glándula antenal, hepatopáncreas, intestino, órgano linfoide, tejido hematopoyético, músculo, gónadas, tejido nervioso, tejido conectivo y corazón. Por último se realizó la tinción de los tejidos con Eosina y Hematoxilina (Morales-Covarrubias, 2004; Lightner, 1996). Estos se analizaron observándolos en un microscopio óptico a aumentos de 100 y 400x.

El procesamiento de los tejidos para histología se realizó en la sección de Patología del Laboratorio Nacional de Servicios Veterinarios (LANASEVE), Servicio Nacional de Salud Animal (SENASA) del Ministerio de Agricultura y Ganadería (MAG) de Costa
Rica. Para este análisis, se fijaron en forma aleatoria un total de cuarenta camarones vivos, mismos que ya presentaban signos clínicos como nado errático o en espiral, letargia y postración sobre uno de los costados de cuerpo. Estos signos clínicos se presentaron en un periodo comprendido entre las seis y las doce horas siguientes a la inoculación de bacterias. La observación de las láminas y su respectivo reporte se realizó en forma conjunta entre el LANASEVE y el Laboratorio de Patologías y Parasitología de Crustáceos.

Grados de severidad: se tomó como criterio de calificación el descrito por Morales-Covarrubias (2004), que da un valor numérico cualitativo del grado de severidad de la infección o lesiones observadas a 400X de magnificación.

Para la clasificación y tipificación de los esferoides en el órgano linfoide o ectópicos, se adaptaron los criterios descritos por Hanson et al. (1999).

\section{RESULTADOS Y DISCUSIÓN}

Del análisis histopatológico realizado en los camarones seleccionados, se obtuvo información producto de las reacciones producidas por la inoculación bacterial, donde se encuentra un grave efecto citopático en los tejidos procesados de Litopenaeus vannamei debido al desarrollo de la infección por $V$. parahaemolyticus. Esto concuerda con los estudios realizados en Penaeus monodon, en los que se encontraron graves daños similares ante la infección de Vibrio harveyi, siendo los principales efectos la formación de nódulos y la agregación de hemocitos con presencia inusual en arterias y senos hemales (Intaraprasong et al., 2009).

El hepatopáncreas (HP) presentó festoneo tubular poco pronunciado en grados 1 y 2 , baja a moderada presencia de bacterias, edemas, nódulos hemocíticos, algunos de ellos melanizados en los senos hemales intertubulares, se evidenció infiltración hemocítica y exfoliación de células epiteliales necróticas (Figura 1A, B y C). El grado de las lesiones observado fue G1-G2, este órgano fue posiblemente favorecido por la ruta de infección empleada, en infecciones crónicas se han reportado daños más pronunciados (Morales-Covarrubias, 2004). Lavilla-Pitogo et al. (1998), mencionan que se sitúa al hepatopáncreas como el órgano blanco ante la infección grave de vibrios luminiscentes en los estanques de cultivo, 

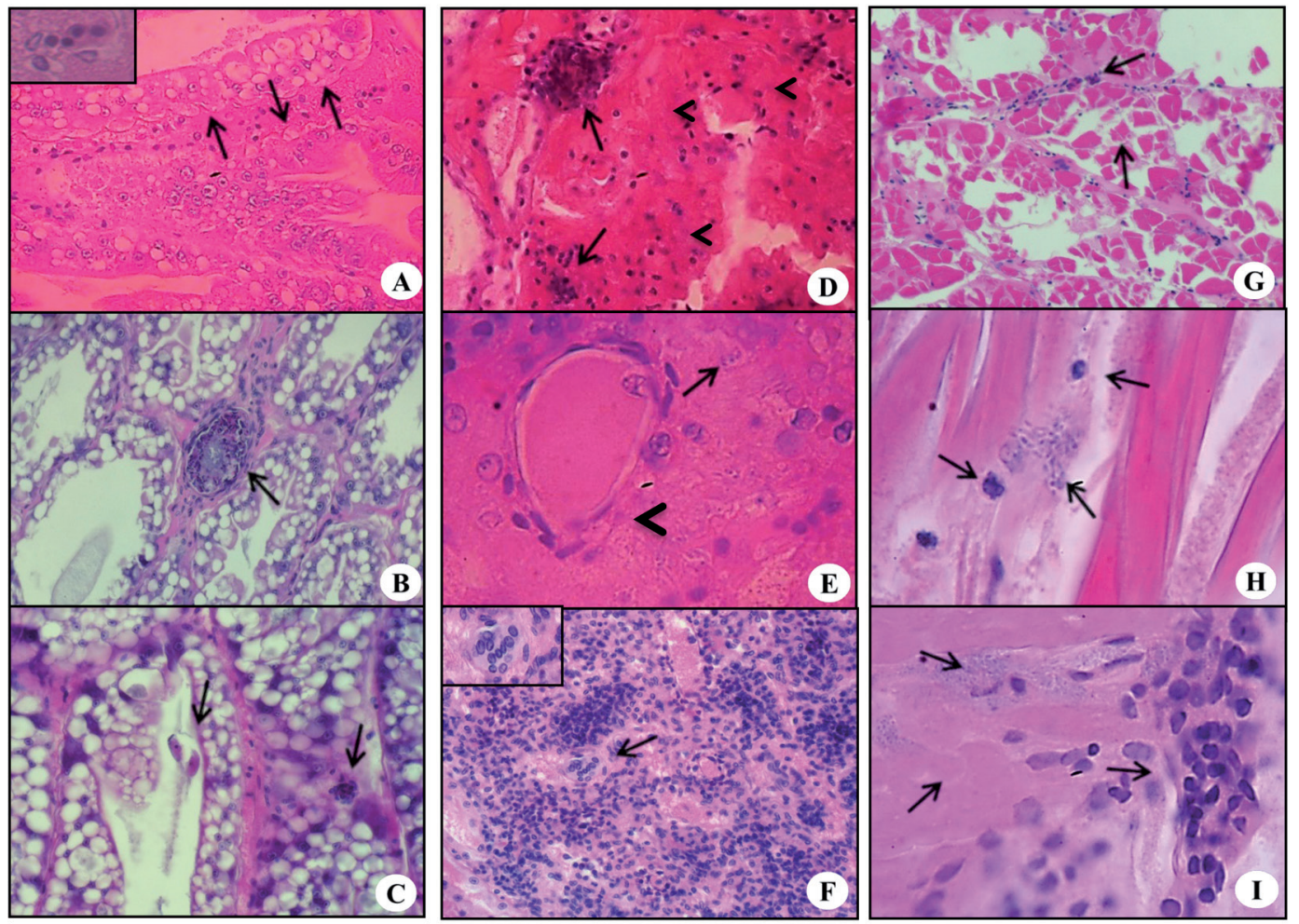

Figura 1. Cortes histológicos de hepatopáncreas, órgano linfoide, músculo en L. vannamei infectados con V. parahaemolyticus. Costa Rica. 2012.

Hepatopáncreas: (A) Los bordes tubulares presentan festoneo y hemocitos picnóticos, el contenido de reservas lipídicas es normal, en el recuadro se observan algunos núcleos picnóticos. (B) Nódulos hemocíticos basofílicos con centros sépticos y melanizados en espacios intertubulares. (C) Nódulos hemocíticos y exfoliación de células epiteliales necróticas, estas células desprendidas presentan núcleos picnóticos (flechas). Órgano linfoide: (D) Nódulos hemocíticos melanizados (flechas), hipereosinofilia, fuerte presencia bacterial (cabezas de flecha) y picnosis generalizada. (E) Material granular intracitoplasmático (cabeza de flecha) y presencia de bacterias teñidas basofílicamente en el espacio estromal (flechas) rodeando el tejido endotelial, presencia de núcleos picnóticos en estroma tubular. (F) Pérdida total de la estructura normal, material eosinofílico, infiltración de hemocitos y esferoides tipo I (recuadro). Músculo estriado: (G) Necrosis coagulativa de las fibras musculares, infiltración de hemocitos en espacios interfasciculares, muchos de estos hemocitos lucen degenerados. (H) Bacterias en espacios intermiocíticos y núcleos picnóticos, se observa la ausencia de las fibras musculares en las zonas de coagulación. (I) Mionecrosis coagulativa severa, alta presencia de bacteria en espacios intersticiales, licuefacción, agregación hemocítica, fibrosis, hipereosinofilia tisular y pérdida de estriación en los miocitos con pérdida consecuente de la capacidad de contracción. Tinción H\&E.

caracterizado por inflamación de los senos intertubulares y presencia de hemocitos, con epitelio tubular necrotizado y alta presencia bacterial. Igualmente, Esteve y Herrera (2000), hallaron alteraciones histológicas en el hepatopáncreas de Farfantepenaeus brasiliensis infectado con $V$. alginolyticus, descritas como degeneración celular y picnosis extensiva, desaparición de acinos tubulares, infiltración hemocítica, formación de granulomas, necrosis y alta acumulación de bacterias.

En el órgano linfoide se generó fibrosis generalizada, dilatación de los senos hemolinfáticos que contenían abundante material eosinofílico, moderada infiltración hemocítica, melanosis, necrosis y licuefacción parenquimal con pérdida total de la estructura tisular. Además se observó 
picnosis parenquimal y endotelial, presencia de bacterias libres en senos hemolinfáticos y espacios intersticiales, cariomegalia hipocrómica, colonización bacterial abundante con necrosis coagulativa en regiones endoteliales, células vacuolizadas, nódulos hemocíticos melanizados y formación de esferoides tipo A, B y C (Figura 1D, E y F). Este tejido fue severamente afectado en todos los animales, debido a su alta vascularización y al constante flujo de hemolinfa. El órgano linfoide ha sido reportado como tejido capaz de capturar patógenos (Hasson et al., 1999; van de Braak et al., 2002) y la ruta de infección utilizada posiblemente facilitó una rápida presencia bacterial en los tejidos fuertemente irrigados, lo que haría esperar mayores daños, tal como se evidenció. El grado de afección de los órganos linfoides fue G4 para todos los animales.

En otro estudio realizado en $P$. monodon pero inoculado con $V$. arguillarum, reportó gran cantidad de hemocitos encapsulando bacterias en el punto de inyección, logrando una disminución de la circulación de estas en hemolinfa; en este caso el órgano linfoide presentó la mayor cantidad de bacterias acumuladas, con alta presencia de células fagocíticas, desgranulación provocada por los hemocitos y alto contenido de esferoides con núcleos picnóticos y células necróticas, esto asociado a la carga infecciosa (van de Braak et al., 2002). De esta manera, se corrobora en esta investigación, la importancia del órgano linfoide como filtro para la captura y aislamiento de los materiales extraños que se encuentran presentes en la hemolinfa.

Se destaca la formación de esferoides en el órgano linfoide, que como mencionan Rusaini y Owens (2010), podría estar relacionado a la tolerancia o resistencia de los camarones ante un agente infeccioso, posiblemente al controlar o reaccionar a ellos. A pesar de lo anterior, estos autores mencionan que la aparición de esferoides se debe a infecciones virales y desestiman su formación a procesos bacteriológicos. Ante tal situación y al analizar las reacciones encontradas en el presente estudio, se sugiere que la formación de esferoides se vincula también a infecciones por agentes bacteriales. Al comparar el estudio de Rusaini y Owens (2010) con lo observado, se confirma la formación de nódulos melanizados como respuesta protectora en los tejidos infectados.

Otro aspecto importante a considerar, es el desempeño del órgano linfoide como las principales estructuras donde se generan reacciones para combatir las afecciones sistémicas (Barraco et al., 2008). Situación reflejada en este estudio histopatológico. Los estudios publicados para este tipo de análisis, demuestran una alta similitud con los hallazgos generados en la presente investigación, confirmando la respuesta del hospedador y la alta patogenicidad de las bacterias pertenecientes al género Vibrio sp. y para el presente caso en estudio específico, a las infecciones sistémicas por la especie $V$. parahaemolyticus.

Con respecto al músculo esquelético, se presentaron áreas extensas de necrosis coagulativa y licuefactiva de las fibras musculares, nódulos hemocíticos melanizados multifocales, pérdida de estriaciones e hipereosinofilia, infiltración de hemocitos, alta colonización bacterial, fibrosis, en algunas muestras se detectaron algunos focos puntuales de infiltración hemocítica en espacios interfasciculares, picnosis difusa (Figura 1G, H e I). Dada la alta carga bacterial, la cantidad, severidad y tipo de lesiones observadas, el grado de afección en el punto de inoculación fue de $\mathrm{G} 4$, para todos los animales procesados.

Como es de esperarse, la zona más afectada se localiza entre el tercero y cuarto segmento abdominal coincidiendo con el punto de inoculación y concentraciones bacteriales extremadamente altas, afectando áreas extensas de tejido muscular, comprometiendo la funcionalidad.

En los cortes realizados en el corazón de los animales procesados y tejidos adyacentes, se observó la formación de nódulos hemocíticos multifocales melanizados o no, con afección en tejido miocárdico y epicárdico, proliferación de fibroblastos e infiltración de hemocitos, picnosis periférica y difusa, fagocitos capturando células picnóticas (Figura 2A, B y C). Este órgano presentó lesiones en grados G1 y G2, sin comprometer, aparentemente, su funcionalidad.

Las muestras de branquias mostraron nódulos hemocíticos multifocales, parcialmente melanizados, tanto en los filamentos primarios como en los secundarios, picnosis periférica, leve infiltración de hemocitos donde se observaban algunos de estos picnóticos en espacios vasculares, procesos fagocíticos, núcleos picnóticos, melanosis y necrosis en lámelas branquiales, así como una fuerte presencia de bacterias libres, indicando una infección activa (Figura 2D, E y F). Se observó con frecuencia moderada, melanosis apical en las lámelas branquiales. La severidad de 


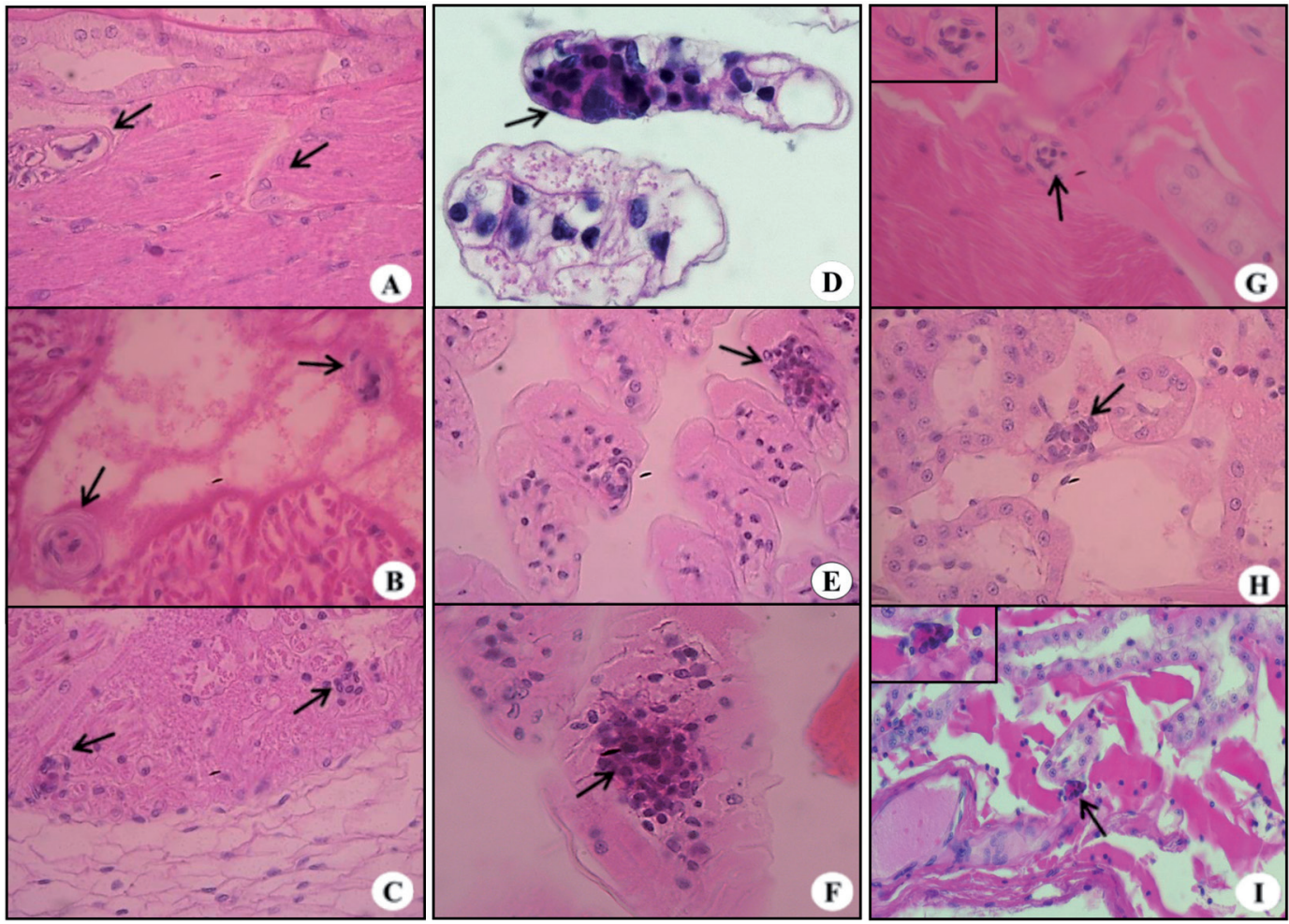

Figura 2. Cortes histológicos de corazón, branquias, glándula antenal en L. vannamei infectados con V. parahaemolyticus. Costa Rica. 2012.

Corazón: (A) Nodulación hemocítica, célula necrótica con núcleo picnótico, hemocito proximal e inicio de respuesta inflamatoria. (B) Nódulo hemocítico sin melanizar en la cámara cardíaca adyacente al miocardio, picnosis y fagocitosis de células necróticas. (C) Nódulos hemocíticos, uno de ellos melanizado en el tejido miocárdico, cercano al epicardio y presencia de núcleos picnóticos. Branquias: (D) Región melanizada con masas de bacterias en su interior. (E) Nódulo hemocítico melanizado en lámina branquial y hemocitos picnóticos en espacios vasculares. (F) Nódulo hemocítico de gran tamaño en lámela branquial, picnosis y necrosis. Glándula antenal: (G) Nódulo hemocítico, subyacente a la glándula antenal (recuadro). (H) Nódulo hemocítico en glándula antenal, picnosis periférica. (I) Dilatación de senos hemolinfáticos, hemocitos y nódulos hemocíticos melanizados. Tinción H\&E.

las lesiones observadas para estas estructuras fue moderada pero consistente, calificándose como G2.

Por su parte, en la glándula antenal se desarrollaron nódulos hemocíticos con presencia en el laberinto, tejidos periféricos y en la región del celomasaco, también se presentó melanosis en tejido conectivo periférico, podocitos picnóticos, agregación hemocítica melanizada o no, prominente dilatación de los senos hemolinfáticos, picnosis e infiltración hemocítica difusa (Figura 2G, H e I). Al igual que en las muestras de los tejidos branquiales, las lesiones fueron moderadas, clasificadas como G2.
En el tejido conectivo se observaron masas de bacterias basofílicas, nódulos hemocíticos melanizados y picnosis, lo anterior principalmente en áreas del tejido conectivo del labrum y el tejido perigástrico. Por último se presentó infiltración hemocítica en tejido conectivo estomacal (Figura 3A, B y C) y se consideró en G3 debido a las lesiones que se presentaron.

Las gónadas en general no presentaron muchas lesiones, aunque fueron visibles algunos nódulos hemocíticos melanizados en ámpula terminal y picnosis en bazo deferente. Mientras que el tejido nervioso presentó en algunos casos picnosis difusa, hemocitos 

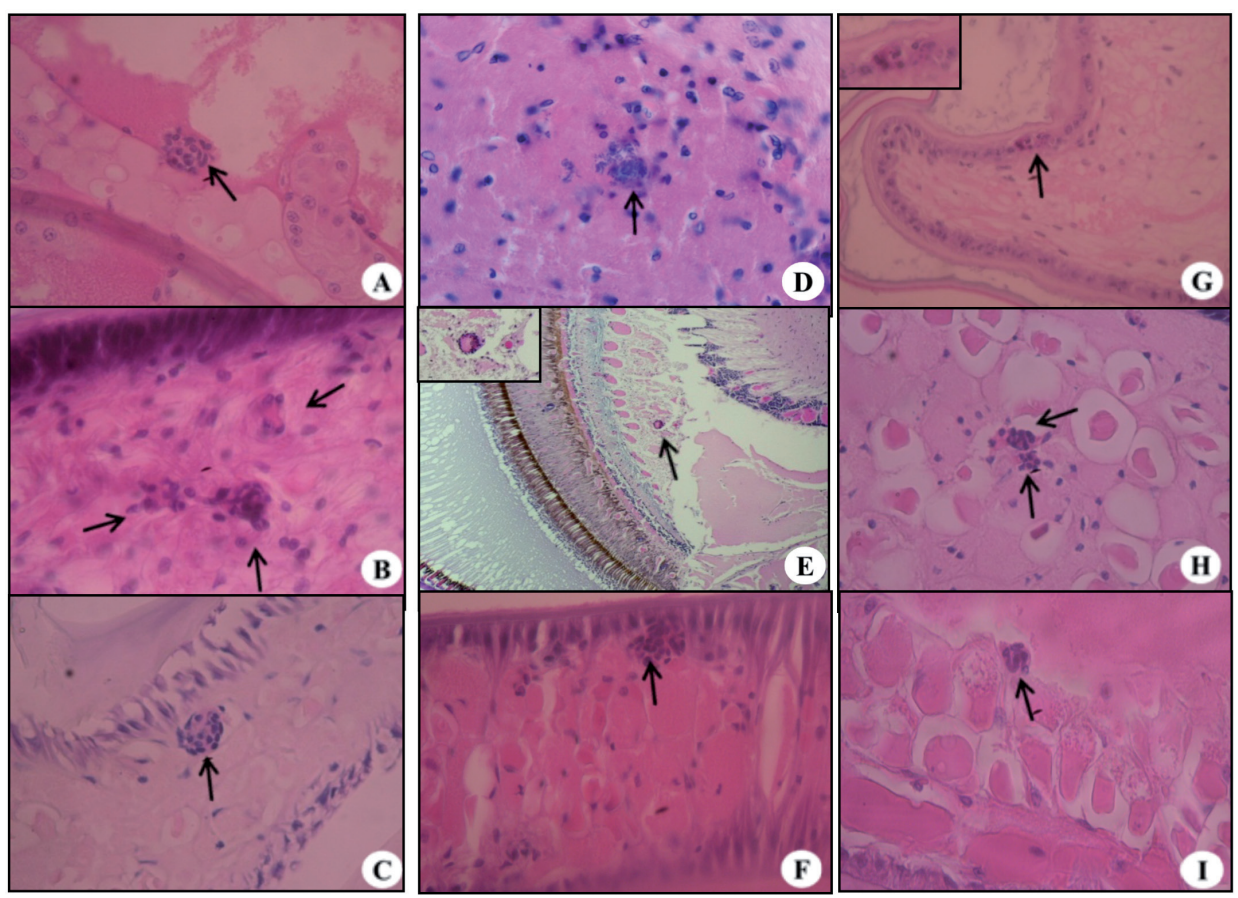

Figura 3. Cortes histológicos de tejido conectivo, tejido nervioso, epitelio cuticular, palpo mandibular en L. vannamei infectados con V. parahaemolyticus. Costa Rica. 2012.

Tejido conectivo: (A) Nódulo hemocítico en tejido conectivo esponjoso de la glándula antenal, perteneciente a la región del laberinto. (B) Pequeños nódulos hemocíticos multifocales en tejido conectivo perigástrico, melanizados. (C) Nódulo hemocítico melanizado, en tejido conectivo perigástrico, adyacente al epitelio. Tejido nervioso: (D) Masas de bacterias en ganglio, necrosis del tejido nervioso con presencia de hemocitos. (E) Nódulo hemocítico melanizado en láminas paraganglionares del globo ocular. Epitelio cuticular: (F) Flagelo antenal con nódulo hemocítico, adyacente al epitelio subcuticular. (G) Nódulo hemocítico en epitelio gástrico. Palpo mandibular: (H) Nódulos hemocíticos multifocales, melanizados. (I) Nódulo hemocítico melanizado formado por hemocitos picnóticos. Tinción $H \& E$.

parcialmente degenerados, nódulos hemocíticos en nervio ocular y en cordón nervioso posterior al ganglio supraesofágico (Figura 3D y E). En todos estos tejidos, el grado de lesión fue leve (G1).

En el epitelio cuticular se apreciaron agregaciones hemocíticas, nódulos hemocitos multifocales, picnosis, además de nódulos hemocíticos en epitelio gástrico y subcuticular (Figura 3F y G). Dada la alta concentración bacterial inoculada y la facilidad de dispersión vía hemolinfa, las lesiones se presentaron en múltiples regiones de los espacios sub cuticulares, con un grado de G2 y 3 .

Soonthornchai et al. (2010) encontraron en L. vannamei con el mismo tipo de vibriosis, pero infectada de forma oral, una fuerte perturbación del epitelio intestinal, asociada a necrosis de la membrana basal e infestación masiva de hemocitos para combatir la infección, además de necrosis de túbulos hepatopancreáticos y encapsulación bacterial. De este estudio es importante resaltar que no hubo daño sistémico en branquias ni corazón.

Otros tejidos procesados evidenciaron la presencia de nódulos hemocíticos, picnosis y necrosis, tales como el palpo mandibular (Figura $3 \mathrm{H}$ e I) y pedúnculo ocular (Figura 4B). El tejido hematopoyético produjo escasos nódulos hemocíticos melanizados, picnosis y melanosis multifocal con bajo impacto en lóbulos (Figura 4A). En los intestinos fue evidente en 

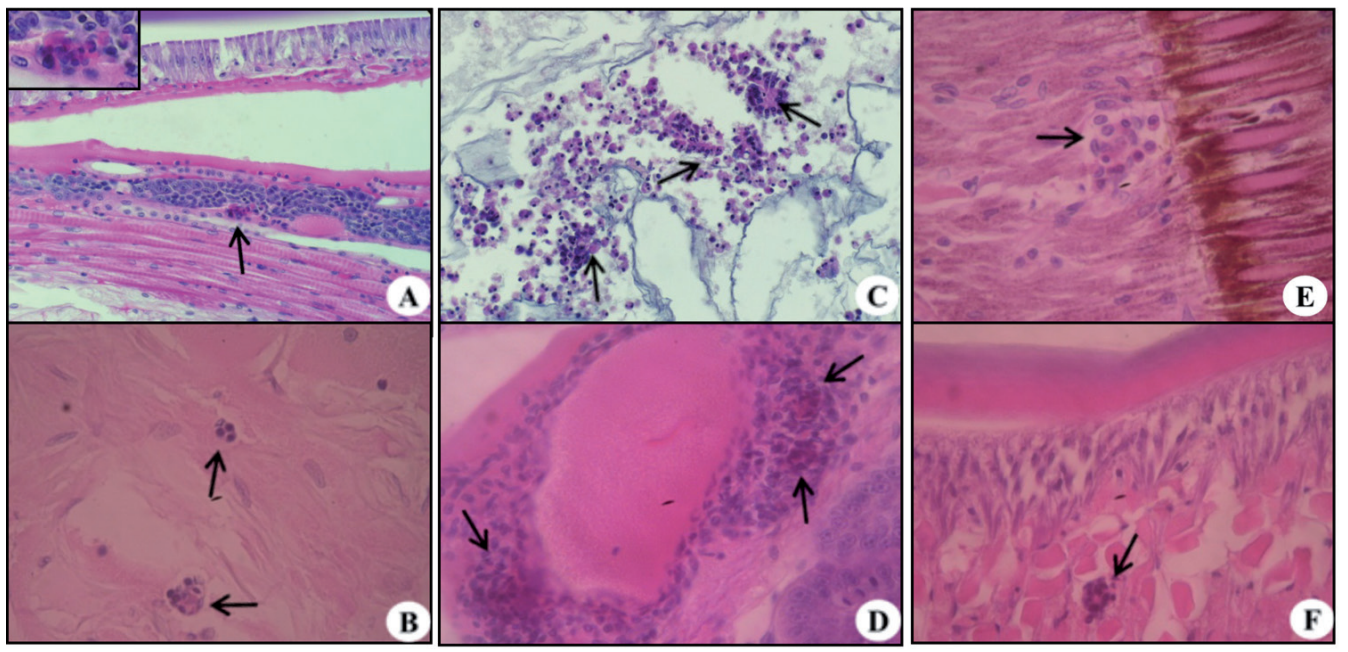

Figura 4. Cortes histológicos de tejido hematopoyético, globo ocular y flagelo antenal en L. vannamei infectados con V. parahaemolyticus. Costa Rica. 2012.

Tejido hematopoyético: (A) Presencia de nódulos hemocíticos (recuadro). Pedúnculo ocular: (B) Nódulos hemocíticos en pedúnculo ocular, picnosis y necrosis. Intestino: (C) Exfoliación de células epiteliales, con presencia bacterial, estas células presentan picnosis y citoplasmas eosinofílicos. Arteria sub-gástrica: (D) Nódulos hemocíticos melanizados. Globo ocular: (E) Nódulo hemocítico, subyacente a los rhabdomas, picnosis y melanosis. Flagelo antenal: (F) Nódulo hemocítico melanizado. Tinción H\&E.

algunos casos, la generación de procesos picnóticos, nódulos hemocíticos melanizados y picnosis en los miocitos longitudinales (Figura 4C). Por otro lado, se presentaron nódulos hemocíticos melanizados en arteria sub-gástrica (Figura 4D), flagelos antenales (Figura 4F) y entre las glándulas tegumentales. En el globo ocular se desarrollaron nódulos hemocíticos subyacentes a los rhabdomas, picnosis y melanosis, aunque sin presencia de bacterias intranodulares $\mathrm{o}$ externas (Figura 4E). Estos tejidos presentaron grados G1 y G2. En todos los casos con una prevalencia menor al $10 \%$ de las muestras.

Al considerar los mecanismos de defensa de los camarones, es importante resaltar el papel que cumplen los hemocitos para combatir a las bacterias patógenas, ya que aparecieron en todas las muestras analizadas en este estudio; estos resultados son similares a los presentados por Esteve y Herrera (2000), van de Braak et al. (2002), Morales (2008) y Soonthornchai et al. (2010).

La formación de esferoides es también considerado un sistema de aislamiento de cuerpos extraños en los camarones, incluyendo agentes virales y bacteriales. Sin embargo, en infecciones severas, es posible que se generen lesiones que imposibiliten la capacidad funcional del órgano, tal como se observó en estos animales, debido a la pérdida total de la estructura del órgano linfoide, incluidas sus zonas vasculares.

Los daños observados en el tejido muscular, sugieren la posible producción y liberación de sustancias citotóxicas por parte de las bacterias, dado el grado de licuefacción y necrosis. Este tipo de lesiones generado por infecciones naturales, puede dar lugar a confusiones con infecciones de virus miófagos, tal como ha sucedido en el pasado en otras regiones (Lemos et al., 2008). Costa Rica no ha reportado la presencia de virus miófagos, a pesar de ser una enfermedad constantemente monitoreada por estar en la lista de declaración obligatoria de la Oficina Internacional de Epizootias (OIE).

La picnosis y melanosis son comunes a muchos órganos y tejidos lesionados, los cuales se presentan como respuesta inespecífica a las infecciones o como consecuencia a los daños tisulares generados por los patógenos. Igualmente, en episodios infecciosos severos pueden comprometer la integridad y funcionalidad de los tejidos del hospedador. 
En lo referente al $V$. parahaemolyticus a pesar de que aun no ha sido diagnosticado en Centroamérica y ser el agente causal de EMS/AHPND, es importante conocer el conjunto de lesiones que ocasiona esta especie bacterial en los camarones de cultivo, como método de reconocimiento. A la vez, se vuelve de mayor relevancia el inicio de las investigaciones que generen información vinculada a esta patología en particular y que puedan generar un diagnóstico oportuno ante un brote, como las mencionadas por Tran et al. (2013).

\section{AGRADECIMIENTOS}

A la Estación Experimental Alfredo Volio Mata (EEAVM) y a la Cooperativa Nacional de Productores de Sal R.L., por el financiamiento del presente trabajo. Al Centro de Investigación en Ciencias del Mar y Limnología (CIMAR) por las facilidades otorgadas en el uso de las instalaciones. A Rocío González del Laboratorio Nacional de Servicios Veterinarios (LANASEVE) y a Norman Rojas de Microbiología Médica de la Universidad de Costa Rica por el apoyo en los análisis y material facilitado. Al Parque Marino del Pacífico por la donación del agua marina. A Ruth Vargas del Centro de Investigaciones en Nutrición Animal por las facilidades otorgadas en la fase práctica de investigación.

\section{LITERATURA CITADA}

Aguirre, G., F. Ascencio, y D. Saulnier. 2005. Pathogenicity of Vibrio penaeicida for white shrimp Litopenaeus vannamei: a cysteine protease-like exotoxin as a virulence factor. J. Dis. Aquat. Org. 67:201-207.

Álvarez, J., B. Austin, A. Alvárez, y C. Agurto. 2000. Especies de Vibrio y Aeromonas aisladas del intestino de camarones marinos sanos silvestres y cultivados en Venezuela. Veterinaria Tropical 25(1):5-27.

Balcázar, J.L. 2002. Uso de probióticos en acuicultura: Aspectos generales. http://www.civa2002.org. (Consultado 17 julio 2010).

Barraco,M.A;Perazzolo,L.M; Rosa.R.D.2008. Inmunología del camarón. En: V. Morales, y J. Cuéllar- Anjel, editores, Guía Técnica - Patología e Inmunología de Camarones Penaeidos. Programa CYTED Red II-D Vannamei, Panamá, República de Panamá. p. 171-224.
Bell, T.A., y D.V. Lightner. 1988. A handbook of normal penaeid shrimp histology. The World Aquaculture Society. Baton Rouge, L.A .

Burge, E.J., D.J. Madigan, L.E. Burnett, y K.G. Burnett. 2007. Lysozyme gene expression by hemocytes of Pacific white shrimp, Litopenaeus vannamei, after injection with Vibrio. Fish Shellfish Immunol. 22: 327-339.

Cuéllar, J. 2008. Métodos de diagnósticos de enfermedades en camarones marinos de cultivo. En: V. Morales, y J. Cuéllar-Anjel, editores, Guía Técnica - Patología e Inmunología de Camarones Penaeidos. Programa CYTED Red II-D Vannamei, Panamá, República de Panamá. p. 1-54.

Decamp, O., D.J. Moriarty, y P. Levens. 2008. Probiotics for shrimp larviculture: review of field data from Asia and Latin America. Aquacult. Res. 39:334-338.

Díaz, J., y M.E. Valerio. 2002. Diarrea por Vibrio parahaemolyticus: primer caso reportado en Costa Rica. Rev. méd. Hosp. Nac. Niños. 37(1-2):15-17.

Esteve, M., y F. Herrera. 2000. Alteraciones histológicas del hepatopáncreas en juveniles de Farfantepenaeus brasiliensis (Latreille, 1817) (Crustacea: Penaeidae) experimentalmente infectados con Vibrio alginolyticus. Saber 12(1):14-20.

FAO. 2010. Penaeus vannamei (Boone, 1931). Programa de información de especies acuáticas. Departamento de Pesca y Acuicultura. http://www.fao.org/ fishery/culturedspecies/Litopenaeus_vannamei/es. (Consultado 30 julio 2010).

FAO. 2013. Report of the FAO/MARD Technical Workshop on Early Mortality Syndrome (EMS) or Acute Hepatopancreatic Necrosis Syndrome (AHPNS) of Cultured Shrimp (under TCP/VIE/3304). Hanoi, Viet Nam, on 25-27 June 2013. FAO Fisheries and Aquaculture Report No. 1053. Rome.

Ganesh, E.A., S. Das, K. Chandrasekar, G. Arun, y S. Balamurugan. 2010. Monitoring of total heterotrophic bacteria and Vibrio spp. in an aquaculture pond. Curr. Res. J. Biol. Sci. 2(1):48-52.

Ibarra, J.C., J. Reyes, L. Galavíz, Z. Molina, y C. Luna. 2003. Vibriosis asociadas al cultivo de camarón Litopenaeus vannamei. En: IX Congreso de ciencia de los alimentos y V Foro de ciencia y tecnología los alimentos. Guanajuato, México. p. 426-430.

Intaraprasong, A., K. Khemayan, T. Pasharawipas, y T.W. Flegel. 2009. Species-specific virulence of Vibrio harveyi for black tiger shrimp is associated with bacteriophage-mediated hemocyte agglutination. Aquaculture 296:185-192. 
Kannapiran, E., J. Ravindran, R. Chandrasekar, y A. KalaiarasI. 2009. Studies on luminous, Vibrio harveyi associated with shrimp culture system rearing Penaeus monodon. J. Environ. Biol. 30(5):791-795.

Hasson, K., D.V. Lightner, L. Mohney, R. Redman, y B. White. 1999. Role of lymphoid organ spheroids in chronic Taura syndrome virus (TSV) Infections in Penaeus vannamei. Dis. Aquat. Org. 38(2):93-105.

Lavilla-Pitogo, C.R., E.M. Leaño, y M.G. Paner. 1998. Mortalities of pond-cultured juvenile shrimp, Penaeus monodon, associated with dominance of luminescent vibrios in the rearing environment. Aquaculture 164: 337-349.

Lemos, A.M., E. Shinozaki, y T.C. Vasconcelos. 2008. Mionecrosis infecciosa viral y sus implicaciones en los cultivos de camarones brasileños. p. 96-103. En: V. Morales, y J. Cuéllar-Anjel, editores, Guía Técnica - Patología e Inmunología de Camarones Penaeidos. Programa CYTED Red II-D Vannamei, Panamá, República de Panamá. 270 p.

Lightner, D.V. 1996. A handbook of shrimp pathology and diagnostic procedures for diseases of cultured penaeid shrimp. World Aquaculture Society, Baton Rouge, LA, USA.

Lightner, D.V., R.M. Redman, C.R. Pantoja, B.L. Noble, y L. Tran. 2012. Early mortality syndrome affects shrimp in Asia. Global Aquaculture Advocate 15(1):40.

Martin, G., N. Rubin, y E. Swanson 2004. Vibrio parahaemolyticus and $V$. harveyi cause detachment of the epithelium from the midgut trunk of the penaeid shrimp Sicyonia ingentis. J. Dis Aquat Org. 60:21-29.

Morales-Covarrubias, M.S. 2004. Enfermedades del camarón: detección mediante análisis en fresco e histopatología. Editorial Trillas, México, D.F.

Morales-Covarrubias, M.S. 2008. Enfermedades bacterianas. En: V. Morales, y J. Cuéllar- Anjel, editores, Guía técnica - patología e inmunología de camarones penaeidos. Programa CYTED Red II-D Vannamei, Panamá, Rep. de Panamá. p. 117-134.

Morales-Covarrubias, M.S. 2013. Camarón análisis en fresco, herramienta de diagnóstico. 1era edición. México. CIAD-OIRSA.

Nelapati, S., K. Nelapati, y B.K. Chinnam. 2012. Vibrio parahaemolyticus- An emerging foodborne pathogen-A Review. Vet. World. 5(1):48-62.

Peña, N., R. Vargas, y A. Varela. 2013. Productos naturales como estimuladores del sistema inmunológico de
Litopenaeus vannamei, infectado com Vibrio parahaemolyticus. Agronomía Mesoamericana 24(1): 133-147.

Rusaini, A., y Owens, L. 2010. Insight into the lymphoid organ of penaeid prawns: A review. Fish Shellfish Immunol. 29:367-377.

Soonthornchai, W., W. Rungrassamee, N. Karoonuthaisiri, P. Jarayabhand, S. Klinbunga, K. Söderhäll, y P. Jiravanichpaisal. 2010. Expression of immune-related genes in the digestive organ of shrimp, Penaeus monodon, after an oral infection by Vibrio harveyi. Dev. Comp. Immunol. 34:19-28.

Soto, S.A., B. Gomez-Gil, y R. Lozano. 2010. 'Brightred' syndrome in Pacific white shrimp Litopenaeus vannamei is caused by Vibrio harveyi. J. Dis. Aquat. Org. 92:11-19.

Soto, S.A., B. Gomez-Gil, R. Lozano, R. del Rio, A. Diéguez, y J. Romalde. 2012. Virulence of Vibrio harveyi responsible for the "Bright-red" Syndrome in the Pacific white shrimp Litopenaeus vannamei. J. of Invert. Pathol. 109:307-317.

Tran, L., L. Nunan, R.M. Redman, y L.L. Mohney, C.R. Pantoja, K. Fitzsimmons, y D.V. Lightner. 2013. Determination of the infectious nature of the agent of acute hepatopancreatic necrosis syndrome affecting penaeid shrimp. Dis. Aquat. Org. 105:45-55.

Trujillo, T., G. Aguirre, G. Sánchez, y J. Rabago. 2005. Patogenicidad de Vibrio parahaemolyticus y Vibrios sp. en juveniles de camarón blanco del Pacífico (Litopenaeus vannamei Boone, 1931). Cienc. Mar IX(27):11-18.

Van de Braak, C.B.T., M.H.A. Botterblom, N. Taverne, W.B. Van Muiswinkel, J.H.W.M. Rombout, y W.P.W. Van der Knaap. 2002. The roles of haemocytes and the lymphoid organ in the clearance of injected Vibrio bacteria in Penaeus monodon shrimp. Fish Shellfish Immunol. 13:293-309.

Zhang, B.C., F. Liu, H.H. Bian, J. Liu, L.Q. Pan, y J. Huang. 2012. Isolation, identification, and pathogenicity analysis of a Vibrio parahaemolyticus strain from Litopenaeus vannamei. (Chinese J.) Progress in Fishery Sciences 33(2):56-62. 
